\title{
Uncertainty analysis for nonpoint source pollution modeling: implications for watershed models
}

\author{
Z. Shen $\cdot$ H. Xie $\cdot$ L. Chen $\cdot$ J. Qiu $\cdot$ \\ Y. Zhong
}

Received: 17 September 2013/Revised: 8 March 2014/Accepted: 21 April 2014/Published online: 7 May 2014

(C) Islamic Azad University (IAU) 2014

\begin{abstract}
Uncertainty is inherent in watershed modeling but it is not fully acknowledged in model applications. This review focuses on uncertainty issues related to the Soil and Water Assessment Tool (SWAT) model, which is one of the most useful tools for simulating nonpoint source (NPS) pollution processes. We considered numerous studies that addressed three types of uncertainty in detail, i.e., the model inputs, parameters, and model structure. It has been shown that rainfall data, in terms of the spatial rainfall variability and the accuracy of the measured data, play a key role in the accuracy of the SWAT model. Geographic information system inputs, including the digital elevation model, land use map, and soil type map, have also been identified as key sources of input errors. With respect to the parameter uncertainty and model structural uncertainty, it is anticipated that the complex, nonlinear structure, and numerous parameters included in the SWAT model may lead to a failure to identify parameters, as well as equifinality phenomenon. We also compared some widely used uncertainty analysis methods, such as the generalized likelihood uncertainty estimation and first-order error analysis, to provide reliable guidance for the application of the SWAT model. This study benefits a wide range of researchers, who are concerned with uncertainty issues in NPS pollution modeling, and it provides insights into the application of watershed models in the development of watershed programs.
\end{abstract}

Z. Shen $(\bowtie) \cdot$ H. Xie · L. Chen · J. Qiu · Y. Zhong

State Key Laboratory of Water Environment Simulation,

School of Environment, Beijing Normal University,

Beijing 100875, People's Republic of China

e-mail: zyshen@bnu.edu.cn
Keywords Model input - Model parameter - Model structure - Soil and Water Assessment Tool - Uncertainty . Uncertainty analysis methods

\section{Introduction}

Nonpoint source (NPS) pollution has been one of the main contributors to water quality degradation during the recent decades (Chen et al. 2013; Tanik et al. 2013; Tian et al. 2012). Watershed models are essential tools that allow researchers to investigate the complex effects of multiple activities on basin systems (Barlund et al. 2007; Ghebremichael et al. 2013). However, watershed managers are often unsure about how well the models match the realworld system that they aim to represent. The meteorological, geological, hydrological, and ecological processes that occur in catchments are highly complex and are not always well known. Given a lack of knowledge and natural randomness, uncertainty is an inherent part of watershed modeling. Overestimating uncertainty can lead to the overconsideration of low probability events and subsequent excessive expenditure on management design, whereas underestimation will lead to substandard pollution reduction (Zhang et al. 2009). Thus, uncertainty in modeling has received much attention because it provides predictions that facilitate high accuracy and precision during watershed management, such as the total maximum daily load and the water framework directive (Chen et al. 2007; Carter and White 2012).

In general, watershed modeling involves two types of uncertainty: (1) systematic modeling uncertainty irrespective of the correct input, or more specifically the uncertainty conferred by the parameters and structure; and (2) uncertainty due to inaccurate inputs. Input errors occur 
due to variations in the natural conditions such as changes in the climate or underlying surface properties (Post et al. 2008; Shen et al. 2013d). Thus, the model inputs should be addressed first, in theory. Parameter and structural uncertainty may be related to the inappropriate application of models in terms of scaling with the hypothesis and design inconsistency (Tripp and Niemann 2008) and to the equifinality phenomena during the complex and subjective process of parameter calibration (Beck 1987). Input errors may be compensated for by parameter calibration, and they may be propagated throughout the model structures, thereby leading to extreme difficulty when decomposing the uncertainty into separate sources (Beven 2006). These different sources of model uncertainty interact and lead to inconclusive results. The propagation effects of these uncertainties are usually calculated based on the standard deviation, coefficient of variation (CV), and uncertainty bands, which should be analyzed to produce reliable predictions (Li et al. 2010). There has been increasing concern about watershed NPS modeling, but the sources of uncertainty and related uncertainty analysis methods have been documented relatively poorly.

The Soil and Water Assessment Tool (SWAT) is a semi-distributed and physically based model (Hong et al. 2012). In general, the hydrological processes in the SWAT model are divided into two phases: the land phase and the channel phase. To estimate the surface runoff, the curve number (CN) method (SCS 1972) is used for the daily rainfall data, and the Green-Ampt infiltration method (Green and Ampt 1991) is used for the hourly precipitation data. The modified universal soil loss equation (MUSLE) model (Williams 1975) is used to estimate the sediment yield at the hydrological research unit (HRU) level. Flow, sediments, and nutrients are combined at the sub-watershed level and routed through the channels, ponds, reservoirs, and wetlands to the watershed outlet using the QUAL2E model (Arabi et al. 2008). The SWAT model is usually selected to simulate NPS processes because it accounts for most of the key processes at the basin scale (Dechmi et al. 2012; Maringanti et al. 2009). More information about the model structures and algorithms used by SWAT was reported by Douglas-Mankin et al. (2010).

Uncertainty analysis has been a hydrological modeling hot spot, but there have been few studies of NPS modeling, especially using the SWAT model. The present study fills this void. In the next section, the sources of uncertainties and their effects on the modeling results are analyzed. The commonly used methods of uncertainty analysis are then compared in terms of their strengths and limitations.

\section{Sources of uncertainty}

\section{Model inputs}

The model inputs are generally considered to be the most important issues that affect watershed models because they drive runoff production and mass transport in the watershed system. Precipitation is considered to be one of the most crucial inputs because it is the direct driving force of the SWAT model (Park et al. 2010). However, rainfall data often exhibit irregular frequencies, durations, and magnitudes across a catchment because of variable natural conditions. The spatial distribution of rainfall, which involves the density of rain gauges and the interpolation methods, can be categorized as an important source of input error. For a typical watershed, it has been reported that the SWAT results may fluctuate as the rain gauge density changes. The $\mathrm{CV}$ of the root mean standard difference (RMSD) based on scenarios with the highest and lowest density may reach up to 0.31 for total phosphorus (Cho et al. 2009). Studies have demonstrated that intensively distributed rain gauges are suitable for obtaining reliable model results, although the construction and operation of large numbers of gauges is problematic and costly (Chaubey et al. 1999, 2005; Masih et al. 2011). However, Gong et al. (2012) found that there were no significant differences between single- and multi-gauge-based hydrology calibrations and validations. This was attributed mainly to the SWAT simulation mechanism in HRUs, which combines many control parameters related to land use, topography, and soil type. They are either distributed uniformly or attenuated by the low resolution of geographic information system (GIS) data in the study area. The parameters obtained using single calibrations can be extrapolated to the whole catchment. However, the determination of the optimal number of rain gauges should consider the watershed characteristics comprehensively. In particular, previous studies provided various quantitative conclusions that are valuable to watershed management. For example, $\mathrm{Fu}$ et al. (2011) reported that the effect of the rainfall input on discharge modeling was relatively low for catchment sizes above $250 \mathrm{~km}^{2}$ and even negligible for watersheds larger than $1,000 \mathrm{~km}^{2}$. A well-located station might be sufficient for watersheds up to about 50 ha (Osborn et al. 1972), while $20 \mathrm{~km}$ has been shown to be the threshold distance between stations to ensure reliable hydrological modeling (Vischel and Lebel 2007).

As a semi-distributed model, the SWAT model automatically assigns precipitation data from the rain gauge nearest to the center of a sub-watershed as the areal rainfall input, which is called the centroid method (Wood et al. 1990). This traditional method may cause inherent 
uncertainties because of the following reasons: Rain gauges far from the centroid of a sub-watershed may be abandoned despite their potential value; the effects of climate variation and elevation change are theoretically important, but are not considered in the current version of SWAT model. Therefore, scientists have attempted to adopt more advanced interpolation methods, which increase the Nash-Sutcliffe efficiency coefficient $\left(\mathrm{E}_{\mathrm{NS}}\right)$ (Nash and Sutcliffe 1970) for flow, sediment, and TP up to 12.5, 10.1, and 9.24\%, respectively (Shen et al. 2012b). These different interpolation methods have resulted in different quantifications of the rainfall spatial variability and the derived uncertainty due to flow modeling. This type of uncertainty may be propagated through the SWAT model, to some extent, to NPS-sediment modeling and then magnified into NPS-nitrogen and NPS-phosphorus modeling. This phenomenon is dominated mainly by the effects of the underlying surface conditions on rainfall-NPS pollution, as well as anthropogenic practices (Cho et al. 2009; Rouhani et al. 2009). Furthermore, there is a need to select an appropriate interpolation method for the scale of interest. Using global interpolators (e.g., the Kriging method and inverse distance-weighted method) with more accurate descriptions of spatial rainfall distributions may have a great positive impact on the model reliability in relatively large watersheds that have high rainfall spatial variability. The current method used in the SWAT model could provide adequate performance if the rainfall regime in small watersheds is mainly homogeneous. It has also been reported that the incorporation of elevation correction factors, which can be extracted from the digital elevation model (DEM), are highly recommended (Masih et al. 2011; Shen et al. 2012b).

Another source of uncertainty in rainfall data is the accuracy of the observed data. In general, rain measurement involves complex physical processes where systematic errors and random errors may arise (Schuurmans and Bierkens 2007). The diversity and complexity of the environment, constraints on the tools used, and a lack of calibration are the leading causes of measurement errors (Liu et al. 2009). The values recorded will inevitably deviate from reality. These errors exist even if the best equipment is used and correct operation is performed (Tapiador et al. 2012). Stochastic modeling may facilitate the investigation of the propagation of rainfall measurement errors. The probability distribution functions (PDFs) of rainfall data errors need to be determined in an appropriate manner based on statistical analysis and the actual conditions (Beven and Alcock 2012).

Watershed hydrology also depends on the land characteristics. The DEM, land use-land cover (LULC), and soil data are the most important inputs used to describe the underlying surface conditions. At present, these spatial data can be visualized explicitly and compiled using the GIS. However, the resolution of GIS data obtained from different departments varies according to the cartography methods used, which leads to high uncertainty. The DEM is a mathematical expression of the topographic conditions, and its resolution affects the parameters extracted from the watershed characteristics, which subsequently has a great impact on model prediction (Chaubey et al. 2005; Dixon and Earls 2009; Lin et al. 2013). The modeling performance potentially improves with increased resolution, but there is a threshold level beyond which the prediction accuracy may fail to improve, and the simulation efficiency may remain stable within a specific resolution domain (Lin et al. 2010). A NPS pollution study in Daning watershed in China's Three Gorges Reservoir Region also confirmed this phenomenon. The contribution of each GIS input to the total uncertainty was decomposed to identify the threshold value. The coarsest resolutions of DEM inputs were assumed to be $200 \times 200 \mathrm{~m}, 90 \times 90 \mathrm{~m}, 30 \times 30 \mathrm{~m}, 90 \times 90 \mathrm{~m}$, and $90 \times 90 \mathrm{~m}$ for modeling the variables flow, sediment, total phosphorus, attached nitrogen, and dissolved nitrogen, respectively (Shen et al. 2013c). The LULC map is used to define the geometric properties and plant cover, whereas the soil data map provides baseline definitions of the soil classes. The threshold phenomenon can also be extended to the LULC and soil map because they are inter-related to the DEM (Shen et al. 2013c). When selecting the optimum combination of resolution for each GIS input, the appropriate resolution at which the model can be assumed to be reliable should be identified as a priority concern. The DEM resolution is considered to be the driving force in SWAT modeling compared with LULC maps. Thus, if high-resolution DEM data can be obtained within the threshold, the choice of precise LULC inputs becomes less important. However, if the resolution of DEM inputs is coarser than the threshold value, LULC maps with finer resolution should be considered. This threshold phenomenon may be explained based on the mechanism employed by the SWAT model. Shen et al. (2013c) suggested that there may be a GIS threshold if the lumped CN and MUSLE application and HRU-based methods are applied to a watershed model. Thus, GIS input with a higher precision might not always be necessary for a semi-distributed model because of the extra cost and labor involved.

\section{Model parameters}

These process-based models are generally treated as conceptualizations of the watershed system functions, so the parameters in these models are defined as quantifiable subprocesses based on the watershed characteristics (Shen et al. 2012a). It has been reported that the model 
parameters comprise conceptual and physical groups (Gong et al. 2011). The conceptual parameters are used to quantify the watershed processes but without physical interpretation. The assignment of their values requires careful calibration. Ideally, physical parameters have physical interpretations based on the watershed processes, and they should be measured or estimated based on the watershed characteristics when intensive data collection are possible. Unknown spatial heterogeneity in the study area and expensive experiments may be involved, so the physical parameters are usually determined by calibrating the model against the measured data. However, if the number of parameters is large because of the substantive sub-processes being considered or the model structure itself, the calibration process becomes complex and parameter uncertainty emerges ( $\mathrm{Ng}$ et al. 2010). Some studies have also shown that the parameter uncertainty may be propagated from hydrological modeling to the NPS simulation to a greater degree (Shen et al. 2008).

Previous studies have demonstrated that only a few parameters have major effects on the model results $(\mathrm{Li}$ et al. 2010; Shen et al. 2008). Moreover, small adjustments of parameters at certain data intervals, especially near the upper and lower limits, introduce significant fluctuations into the model results (Harrison et al. 1993; Shen et al. 2012a). In an actual application of the SWAT model, it is preferable to obtain the confidence range of each parameter and so the models can be calibrated appropriately. Parameter calibration is a complex, nonlinear problem, and numerous possible solutions may be obtained using optimization algorithms. Previous studies (Arhonditsis et al. 2008; Zak and Beven 1999) suggest that multiple disjoint groups of parameters may produce similar model results, which is widely known as equifinality because input errors and structural uncertainties may neutralize the discrepancies caused by the parameters (Beven and Binley 1992). In these cases, the model user should check whether any information related to the watershed characteristics and its underlying hydrological processes, or neighboring catchments, could be used to provide more precise statistical ranges for the model parameters.

Determining the PDF for each parameter is another critical step during parameter uncertainty analysis. In ideal cases, if intensive data collection are possible, the PDF of each parameter should be measured or estimated according to the watershed characteristics. However, these experiments are often impossible for many reasons, such as the unknown spatial heterogeneity of the watershed, high costs, and time constraints, as well as the experience of the operating personnel involved (Nandakumar and Mein 1997). Instead, researchers collect and estimate PDFs using statistical processes. From the perspective of statistical parameter estimation, the question could be rephrased as the problem of selecting the appropriate PDFs for parameters. According to Sohrabi et al. (2003), PDFs can be determined according to professional judgment and based on documented information. In general, theoretical and empirical PDFs can be used instead of data collection and monitoring. For example, the soil hydraulic conductivity was shown to be approximately log-normally distributed in some studies (Sohrabi et al. 2003). It is usual to employ classic PDFs, such as uniform, normal, and logarithmic normal, to evaluate the propagation of parameter uncertainty to the model outputs (Vrugt et al. 2003). In a study that focused on the influence of parameter distribution uncertainty (Shen et al. 2013a), a uniform PDF produced the widest stream flow $95 \%$ confidence interval (CI) $\left(0.92-53.11 \mathrm{~m}^{3} / \mathrm{s}\right)$, followed by logarithmic normal PDF $\left(37.59-56.91 \mathrm{~m}^{3} / \mathrm{s}\right)$ and normal PDF $\left(38.04-56.94 \mathrm{~m}^{3} / \mathrm{s}\right)$. The wider $95 \%$ CI with a uniform PDF might lead to a more uncertain model prediction. For a uniform PDF, however, the $\mathrm{E}_{\mathrm{NS}}$ was calculated as $(-0.27604,0.74314)$, which included the most satisfactory results. In sediment simulations, the PDF types produced the same effects. Based on this study, the selection of parameter PDFs might allow a balance between modeling precision and prediction uncertainty. An adequate number of simulations is also required to satisfy the convergence precision and to calculate more reliable distributions. To reduce this burden, the integration of an appropriate sampling method is also beneficial.

Specifically, the contamination caused by NPS differs greatly among land use types. Therefore, land use parameters are important during NPS modeling. Studies have shown that the uncertainty of NPS outputs exhibits apparent variation among different land use types because of their different landforms, physiognomy, underlying surface conditions, and anthropogenic activities (Shen et al. 2010, 2013b; Tu 2011). Thus, parameter uncertainty analysis can facilitate effective management. Various attempts have been made in this respect in the Three Gorges Reservoir Region of China. It has been demonstrated that dry land is highly recommended with conservation practices and appropriate land cover, while nutrient management should be optimized in paddy fields. The grazing practices and vegetation density are considered to be especially important for yellow earth and purple soils, respectively. It has also been shown that NPS prediction has a greater uncertainty during high-flow periods ( $\mathrm{Li}$ et al. 2009; Shen et al. 2008; Wu and Liu 2012). The main cause is the irregular frequency of precipitation and stream flows, which propagate uncertainty into the NPS outputs (Bardossy and Das 2008; Shen et al. 2008). 
Table 1 Comparison of common-used methods for uncertainty analysis

\begin{tabular}{|c|c|c|c|c|}
\hline \multirow[t]{2}{*}{ Methods } & \multirow[t]{2}{*}{ Principles } & \multicolumn{3}{|c|}{ Critical considerations } \\
\hline & & $\begin{array}{l}\text { System } \\
\text { nonlinearity }\end{array}$ & $\begin{array}{l}\text { Correlation of } \\
\text { elements }\end{array}$ & $\begin{array}{l}\text { Assumption } \\
\text { of PDF }\end{array}$ \\
\hline OTA & Each variable is perturbed in turn with all other factors fixed & & & $\sqrt{ }$ \\
\hline FOEA & $\begin{array}{l}\text { First-order derivative of the function with respect to elements acting } \\
\text { independently }\end{array}$ & & & $\sqrt{ }$ \\
\hline SUFI-2 & Propagation of parameter uncertainty leads to $95 \%$ prediction uncertainty & $\sqrt{ }$ & $\sqrt{ }$ & $\sqrt{ }$ \\
\hline $\mathrm{MC}$ & Each uncertain characteristic is randomly selected from a PDF & $\sqrt{ }$ & $\sqrt{ }$ & $\sqrt{ }$ \\
\hline GLUE & $\begin{array}{l}\text { MC-based sampling followed by estimation with likelihood measures and } \\
\text { threshold value }\end{array}$ & $\sqrt{ }$ & $\sqrt{ }$ & $\sqrt{ }$ \\
\hline $\begin{array}{l}\text { Bayesian } \\
\text { inference }\end{array}$ & $\begin{array}{l}\text { Probability density of the posterior parameter distribution is derived from the } \\
\text { prior density and measured data }\end{array}$ & $\sqrt{ }$ & $\sqrt{ }$ & \\
\hline Bootstrap & Nonparametric technique with direct sampling from data & & & \\
\hline
\end{tabular}

\section{Model structure}

Structural uncertainty arises from inaccurate descriptions of watershed systems. It is widely held that the details of watershed processes cannot be captured fully by watershed models because of the complex mechanism of NPS pollution, so the simplification of some processes (e.g., runoff production, infiltration, and evapotranspiration) is inevitable. Studies have shown that the model structure may even produce a greater magnitude of uncertainty than other sources (Li et al. 2010; Parasuraman and Elshorbagy 2008). In general, the development and modification of modules according to actual modeling procedures is a common approach for addressing structural uncertainty (Pohlert et al. 2007). In particular, the SWAT model includes different built-in modules that represent the same watershed processes. According to Zhang et al. (2009), different descriptions of evapotranspiration, flow routing, snow accumulation, and melting could be merged in the SWAT model. The Bayesian model averaging (BMA) mean and ensemble mean were calculated, and both yielded better prediction accuracy than single model-based results in terms of $\mathrm{E}_{\mathrm{NS}}$.

\section{Methods of uncertainty analysis}

Several calibration and uncertainty analysis techniques have been applied in previous studies. Table 1 shows the most commonly used methods. The appropriate choices should be based on three critical considerations: (1) the system nonlinearity; (2) the correlations among elements; and (3) the assumptions of the PDFs. The features of each method are discussed in greater detail below based on these three considerations, as well as the strengths and limitations characterized in Table 2.
Table 2 Strengths and limitations of each analysis method

\begin{tabular}{|c|c|c|c|}
\hline Methods & Strengths & Limitations & References \\
\hline OTA & $\begin{array}{l}\text { Easy to program, } \\
\text { low } \\
\text { computational } \\
\text { requirements }\end{array}$ & $\begin{array}{l}\text { Biased results in } \\
\text { non-linear system }\end{array}$ & $\begin{array}{l}\text { Morris } \\
\text { (1991) }\end{array}$ \\
\hline FOEA & $\begin{array}{l}\text { Easy to use, } \\
\text { simple } \\
\text { algorithms }\end{array}$ & $\begin{array}{l}\text { Many hypotheses } \\
\text { are adopted, } \\
\text { biased results in } \\
\text { non-linear system }\end{array}$ & $\begin{array}{l}\text { Abbaspour } \\
\text { et al. } \\
\text { (2004) }\end{array}$ \\
\hline SUFI-2 & $\begin{array}{l}\text { Semi-automated; } \\
\text { all sources of } \\
\text { uncertainty are } \\
\text { accounted for }\end{array}$ & $\begin{array}{l}\text { Parameter PDFs are } \\
\text { prejudged, } \\
\text { additional } \\
\text { iterations are } \\
\text { required }\end{array}$ & $\begin{array}{l}\text { Melching } \\
\text { and Yoon } \\
(1996)\end{array}$ \\
\hline MC & $\begin{array}{l}\text { Flexible, simple, } \\
\text { but sound }\end{array}$ & $\begin{array}{l}\text { Abundant } \\
\text { simulation times } \\
\text { are required }\end{array}$ & $\begin{array}{l}\text { Bobba } \\
\text { et al. } \\
(2000)\end{array}$ \\
\hline GLUE & $\begin{array}{l}\text { All sources of } \\
\text { uncertainty are } \\
\text { accounted for }\end{array}$ & $\begin{array}{l}\text { Huge sampling } \\
\text { quantity, many } \\
\text { hypotheses are } \\
\text { adopted }\end{array}$ & $\begin{array}{l}\text { Beven and } \\
\text { Binley } \\
(1992)\end{array}$ \\
\hline $\begin{array}{l}\text { Bayesian } \\
\text { inference }\end{array}$ & $\begin{array}{l}\text { PDFs are strictly } \\
\text { estimated }\end{array}$ & $\begin{array}{l}\text { Strong dependence } \\
\text { on the formulation } \\
\text { of likelihood } \\
\text { function }\end{array}$ & $\begin{array}{l}\text { Vrugt et al. } \\
(2003)\end{array}$ \\
\hline Bootstrap & $\begin{array}{l}\text { Wide scope of } \\
\text { application, } \\
\text { fewer } \\
\text { assumptions are } \\
\text { involved }\end{array}$ & $\begin{array}{l}\text { High dependency } \\
\text { on original } \\
\text { samples }\end{array}$ & $\begin{array}{l}\text { Li et al. } \\
(2010)\end{array}$ \\
\hline
\end{tabular}

Sensitivity analysis (SA) is a screening method used to estimate the response degree of model results with respect to a certain parameter (Spear and Hornberger 1980). However, one-factor-at-a-time (OTA) is a traditional SA technique that fails to appreciate the spatial distributions and correlations among parameters, which may lead to biased results with nonlinear systems (Morris 1991). 
Studies have also indicated that rankings based on sensitivity may not match with those based on uncertainty, which may lead to parameters with low sensitivity but high uncertainty being overlooked (Beck 1987; Melching and Yoon 1996; Shen et al. 2008).

The first-order error analysis (FOEA) method, which considers the combined effects of parameter sensitivity and uncertainty, has gained popularity in situations where insufficient information is available (Melching and Yoon 1996; Zhao et al. 2011). Compared with other methods, the greatest strength of FOEA is the simplicity of the algorithms it employs, although the inherent constraints that underlie the assumptions of the system functions are linear (Bobba et al. 1996; Shen et al. 2010).

A uniform distribution is assumed in the sequential uncertainty fitting version 2 (SUFI-2) method, and the uncertainty is quantified using $95 \%$ prediction uncertainty (Abbaspour et al. 2004). This process begins with an assumption of high uncertainty and reduces the range, either by bracketing most of the observations or when the average distance between the simulation and measurements becomes small. The SUFI-2 algorithm considers all sources of uncertainty, but it requires additional iterations and careful adjustment of the parameter ranges (Setegn et al. 2010)

The Monte Carlo (MC) technique is conceptually simple but theoretically sound, and it supports stochastic analysis using perturbation approaches (Bobba et al. 2000). High-precision estimation depends on the sampling number. The MC-based techniques, which are typified by importance sampling (IS) and Markov Chain MC (MCMC) simulations, consider the nonlinearity and interdependency among components, and they are commonly integrated into more synthetic approaches such as the generalized likelihood uncertainty estimation (GLUE) method and Bayesian inference ( $\mathrm{Li}$ et al. 2010). Bayesian inference derives the posterior parameter PDF based on the prior distribution and a likelihood function (Vrugt et al. 2003). The model nonlinearity with arbitrary posterior distribution shapes is better described using MC-based numerical approximations that consider parameter spaces with high dimensions (Yang et al. 2007). Compared with the Bayesian inference method, the bootstrap method may involve even fewer assumptions, especially when the error form is hard to derive or approximate. As a nonparametric technique, it depends heavily on the original data but the correlations among elements might not be preserved $(\mathrm{Li}$ et al. 2010).

The GLUE method (Beven and Binley 1992) is based on the concept of IS and regional SA. It stresses that the model performance depends on the parameter sets rather than the individual parameters by considering all sources of uncertainty including input errors, parameters, and structural uncertainty (Vrugt et al. 2009). However, its prohibitive computational burden hinders its application to some extent. Moreover, several subjective hypotheses, such as the variation ranges of parameters, the level of confidence, the likelihood function, and the threshold value of the likelihood measure, need to be investigated further to obtain a reliable estimation (Gong et al. 2011).

\section{Conclusion}

Our study reflects the concerns of watershed decisionmakers and highlights the significance of targeting uncertainty, which is an inherent part of NPS modeling. The consideration of model input uncertainty facilitates input data acquisition and data processing. The number and locations of rainfall gauges, as well as interpolation methods for the scale of interest, should be selected carefully and arranged to provide accurate description of rainfall variability. Rainfall measurement errors should not be neglected because of their propagation and magnified effect in flow and NPS modeling. The optimum combination of GIS data resolution should be determined in terms of the threshold phenomenon, to guide watershed managers when building spatial databases. As another significant source of uncertainty, the model parameters involve inherent uncertainty and propagation effects in the same manner as rainfall data. Parameter identification in terms of their sensitivity, uncertainty, and PDFs helps to characterize significant NPS processes and to guide appropriate effective management practices. In addition, the uncertainty caused by model structures may be treated by replacing single results with ensemble or BMA means.

In an actual application, the sources of uncertainty should be analyzed by stochastic simulation to identify the components of models that can be updated to achieve the optimal assimilation of the real-world observation, thereby facilitating dynamic decision making. The use of uncertainty bands rather than specific values can avoid biased predictions, although the trade-off between the confidence interval and the uncertainty bound required to meet management requirements in all potential situations remains a subjective but critical issue. It should be mentioned that the majority of previous studies have focused on parameter uncertainty. However, the model input and structure uncertainties merit greater attention. The impact of each source of uncertainty is also difficult to separate because of the potential for compensating errors among them. The interactions between these sources of uncertainty remain a challenge that prevents a holistic understanding of uncertainty issues. The uncertainty associated with a specific source will also be magnified from discharge modeling to 
NPS modeling, to varying extents, because the SWAT model is a nonlinear system, which reflects the importance of addressing uncertainty issues in NPS modeling. The results highlighted in this review can be extrapolated to other watershed models, such as the Agricultural Nonpoint Source (AGNPS) model and Hydrological Simulation Program-FORTRAN (HSPF) model, which share many similarities with NPS simulation systems. Future work should use advanced techniques to improve our understanding of NPS processes.

Acknowledgments The study was funded by several grants from the National Science Foundation for Distinguished Young Scholars (No. 51025933), the National Science Foundation for Innovative Research Group (No. 51121003), and the National Basic Research Program of China (973 Project, 2010CB429003).

\section{References}

Abbaspour KC, Johnson CA, Van Genuchten MT (2004) Estimating uncertain flow and transport parameters using a sequential uncertainty fitting procedure. Vadose Zone J 3(4):1340-1352

Arabi M, Frankenberger JR, Engel BA, Arnold JG (2008) Representation of agricultural conservation practices with SWAT. Hydrol Process 22(16):3042-3055

Arhonditsis GB, Perhar G, Zhang W, Massos E, Shi M, Das A (2008) Addressing equifinality and uncertainty in eutrophication models. Water Resour Res 44(1):W01420

Bardossy A, Das T (2008) Influence of rainfall observation network on model calibration and application. Hydrol Earth Syst Sci 12(1):77-89

Barlund I, Kirkkala T, Malve O, Kamari J (2007) Assessing SWAT model performance in the evaluation of management actions for the implementation of the Water Framework Directive in a Finnish catchment. Environ Model Softw 22(5):719-724

Beck MB (1987) Water quality modeling: a review of the analysis of uncertainty. Water Resour Res 23(8):1393-1442

Beven K (2006) A manifesto for the equifinality thesis. J Hydrol $320(1-2): 18-36$

Beven KJ, Alcock RE (2012) Modelling everything everywhere: a new approach to decision-making for water management under uncertainty. Freshw Biol 57(s1):124-132

Beven K, Binley A (1992) The future of distributed models-model calibration and uncertainty prediction. Hydrol Process 6(3):279-298

Bobba AG, Singh VP, Bengtsson L (1996) Application of first-order and monte carlo analysis in watershed water quality models. Water Resour Manag 10(3):219-240

Bobba AG, Singh VP, Bengtsson L (2000) Application of environmental models to different hydrological systems. Ecol Model 125(1):15-49

Carter JG, White I (2012) Environmental planning and management in an age of uncertainty: the case of the Water Framework Directive. J Environ Manage 113:228-236

Chaubey I, Haan CT, Salisbury JM, Grunwald S (1999) Quantifying model output uncertainty due to spatial variability of rainfall. J Am Water Resour Assoc 35(5):1113-1123

Chaubey I, Cotter AS, Costello TA, Soerens TS (2005) Effect of DEM data resolution on SWAT output uncertainty. Hydrol Process 19(3):621-628
Chen CF, Ma HW, Reckhow KH (2007) Assessment of water quality management with a systematic qualitative uncertainty analysis. Sci Total Environ 374(1):13-25

Chen L, Liu RM, Huang Q, Chen YX, Gao SH, Sun CC, Shen ZY (2013) Integrated assessment of nonpoint source pollution of a drinking water reservoir in a typical acid rain region. Int $\mathrm{J}$ Environ Sci Technol 10(4):651-664

Cho J, Bosch D, Lowrance R, Strickland T, Vellidis G (2009) Effect of spatial distribution of rainfall on temporal and spatial uncertainty of SWAT output. Trans ASABE 52(5):1545-1555

Dechmi F, Burguete J, Skhiri A (2012) SWAT application in intensive irrigation systems: model modification, calibration and validation. J Hydrol 470:227-238

Dixon B, Earls J (2009) Resample or not?! Effects of resolution of DEMs in watershed modeling. Hydrol Process 23(12): $1714-1724$

Douglas-Mankin KR, Srinivasan R, Arnold JG (2010) Soil and Water Assessment Tool (SWAT) model: current developments and applications. Trans ASABE 53(5):1423-1431

$\mathrm{Fu} \mathrm{S}$, Sonnenborg TO, Jensen KH, He X (2011) Impact of precipitation spatial resolution on the hydrological response of an integrated distributed water resources model. Vadose Zone $\mathrm{J}$ 10(1):25-36

Ghebremichael LT, Veith TL, Hamlett JM (2013) Integrated watershed- and farm-scale modeling framework for targeting critical source areas while maintaining farm economic viability. J Environ Manage 114:381-394

Gong Y, Shen Z, Hong Q, Liu R, Liao Q (2011) Parameter uncertainty analysis in watershed total phosphorus modeling using the GLUE methodology. Agric Ecosyst Environ 142(3-4):246-255

Gong Y, Shen Z, Liu R, Hong Q, Wu X (2012) A comparison of single- and multi-gauge based calibrations for hydrological modeling of the Upper Daning River Watershed in China's Three Gorges Reservoir Region. Hydrol Res 43(6):822-832

Green WH, Ampt GA (1911) Studies on soil physics, 1. The flow of air and water through soils. J Agric Sci 4(1):11-24

Harrison RM, Lambert GD, Chapple CL (1993) Spectral estimation and contrast calculation in the design of contrast-detail test objects for radiotherapy portal imaging. Phys Med Biol 38(4):545-556

Hong Q, Sun Z, Chen L, Liu RM, Shen ZY (2012) Small-scale watershed extended method for non-point source pollution estimation in part of the Three Gorges Reservoir Region. Int J Environ Sci Technol 9(4):595-604

Li Z, Xu Z, Shao Q, Yang J (2009) Parameter estimation and uncertainty analysis of SWAT model in upper reaches of the Heihe river basin. Hydrol Process 23(19):2744-2753

Li Z, Shao Q, Xu Z, Cai X (2010) Analysis of parameter uncertainty in semi-distributed hydrological models using bootstrap method: a case study of SWAT model applied to Yingluoxia watershed in northwest China. J Hydrol 385(1-4):76-83

Lin S, Jing C, Coles NA, Chaplot V, Moore NJ, Wu J (2013) Evaluating DEM source and resolution uncertainties in the Soil and Water Assessment Tool. Stoch Environ Res Risk Assess 27(1):209-221

Liu Y, Freer J, Beven K, Matgen P (2009) Towards a limits of acceptability approach to the calibration of hydrological models: extending observation error. J Hydrol 367(1-2):93-103

Lin S, Jing C, Chaplot V, Yu X, Zhang Z, Moore N, Wu J (2010) Effect of DEM resolution on SWAT outputs of runoff, sediment and nutrients. Hydrol Earth Syst Sci Discuss 7(4):4411-4435

Maringanti C, Chaubey I, Popp J (2009) Development of a multi objective optimization tool for the selection and placement of best management practices for nonpoint source pollution control. Water Resour Res 45(6):W06406. doi:10.1029/2008WR007094 
Masih I, Maskey S, Uhlenbrook S, Smakhtin V (2011) Assessing the impact of areal precipitation input on streamflow simulations using the SWAT Model1. J Am Water Resour Assoc 47(1):179-195

Melching CS, Yoon CG (1996) Key sources of uncertainty in QUAL2E model of Passaic River. J Water Resour Plan ASCE 122(2):105-113

Morris MD (1991) Factorial sampling plans for preliminary computational experiments. Technometrics 33(2):161-174

Nandakumar N, Mein RG (1997) Uncertainty in rainfall-runoff model simulations and the implications for predicting the hydrologic effects of land-use change. J Hydrol 192(1-4):211-232

Nash JE, Sutcliffe JV (1970) River flow forecasting through conceptual models: part 1. A discussion of principles. J Hydrol 10(3):282-290

$\mathrm{Ng}$ TL, Eheart JW, Cai XM (2010) Comparative calibration of a complex hydrologic model by stochastic methods GLUE and PEST. Trans ASABE 53(6):1773-1786

Osborn HB, Hundley JF, Lane LJ (1972) Optimum gaging of thunderstorm rainfall in southeastern arizona. Water Resour Res 8(1):259-265

Parasuraman K, Elshorbagy A (2008) Toward improving the reliability of hydrologic prediction: model structure uncertainty and its quantification using ensemble-based genetic programming framework. Water Resour Res 44(12):W12406

Park JH, Duan L, Kim B, Mitchell MJ, Shibata H (2010) Potential effects of climate change and variability on watershed biogeochemical processes and water quality in Northeast Asia. Environ Int 36(2):212-225

Pohlert T, Huisman JA, Breuer L, Frede HG (2007) Integration of a detailed biogeochemical model into SWAT for improved nitrogen predictions-model development, sensitivity, and GLUE analysis. Ecol Model 203(3-4):215-228

Post J, Hattermann FF, Krysanova V, Suckow F (2008) Parameter and input data uncertainty estimation for the assessment of long-term soil organic carbon dynamics. Environ Model Softw 23(2):125-138

Rouhani H, Willems P, Feyen J (2009) Effect of watershed delineation and areal rainfall distribution on runoff prediction using the SWAT model. Hydrol Res 40(6):505-519

Schuurmans JM, Bierkens MFP (2007) Effect of spatial distribution of daily rainfall on interior catchment response of a distributed hydrological model. Hydrol Earth Syst Sci 11(2):677-693

SCS, Us. (1972) National engineering handbook, section 4: hydrology. USPGO, Washington

Setegn SG, Srinivasan R, Melesse AM, Dargahi B (2010) SWAT model application and prediction uncertainty analysis in the Lake Tana Basin, Ethiopia. Hydrol Process 24(3):357-367

Shen ZY, Hong Q, Yu H (2008) Parameter uncertainty analysis of the non-point source pollution in the Daning River watershed of the Three Gorges Reservoir Region, China. Sci Total Environ 405(1-3): 195-205

Shen ZY, Hong Q, Yu H, Niu JF (2010) Parameter uncertainty analysis of non-point source pollution from different land use types. Sci Total Environ 408(8):1971-1978

Shen ZY, Chen L, Chen T (2012a) Analysis of parameter uncertainty in hydrological and sediment modeling using GLUE method: a case study of SWAT model applied to Three Gorges Reservoir Region, China. Hydrol Earth Syst Sci 16(1):121-132

Shen ZY, Chen L, Liao Q, Liu R, Hong Q (2012b) Impact of spatial rainfall variability on hydrology and nonpoint source pollution modeling. J Hydrol 472:205-215

Shen ZY, Chen L, Chen T (2013a) The influence of parameter distribution uncertainty on hydrological and sediment modeling: a case study of SWAT model applied to the Daning watershed of the Three Gorges Reservoir Region, China. Stoch Environ Res Risk Assess 27(1):235-251

Shen ZY, Chen L, Hong Q, Qiu J, Xie H, Liu R (2013b) Assessment of nitrogen and phosphorus loads and causal factors from different land use and soil types in the Three Gorges Reservoir Area. Sci Total Environ 454-455:383-392

Shen ZY, Chen L, Liao Q, Liu RM, Huang Q (2013c) A comprehensive study of the effect of GIS data on hydrology and non-point source pollution modeling. Agric Water Manage 118:93-102

Shen ZY, Huang Q, Liao Q, Chen L, Liu RM, Xie H (2013d) Uncertainty in flow and water quality measurement data: a case study in the Daning River watershed of the Three Gorges Reservoir Region, China. Desalin Water Treat 51(19-21):3995-4001

Sohrabi T, Shirmohammadi A, Chu T, Montas H, Nejadhashemi A (2003) Uncertainty analysis of hydrologic and water quality predictions for a small watershed using SWAT2000. Environ Forensics 4(4):229-238

Spear R, Hornberger G (1980) Eutrophication in Peel Inlet-II. Identification of critical uncertainties via generalized sensitivity analysis. Water Res 14(1):43-49

Tanik A, Ozalp D, Seker DZ (2013) Practical estimation and distribution of diffuse pollutants arising from a watershed in Turkey. Int J Environ Sci Technol 10(2):221-230

Tapiador FJ, Turk FJ, Petersen W, Hou AY, García-Ortega E, Machado LAT, Angelis CF, Salio P, Kidd C, Huffman GJ, de Castro M (2012) Global precipitation measurement: methods, datasets and applications. Atmos Res 104:70-97

Tian P, Zhao G, Li J, Gao J, Zhang Z (2012) Integration of monthly water balance modeling and nutrient load estimation in an agricultural catchment. Int J Environ Sci Technol 9(1):163-172

Tripp DR, Niemann JD (2008) Evaluating the parameter identifiability and structural validity of a probability-distributed model for soil moisture. J Hydrol 353(1-2):93-108

Tu J (2011) Spatially varying relationships between land use and water quality across an urbanization gradient explored by geographically weighted regression. Appl Geogr 31(1):376-392

Vischel T, Lebel T (2007) Assessing the water balance in the Sahel: impact of small scale rainfall variability on runoff. Part 2: Idealized modeling of runoff sensitivity. J Hydrol 333(2-4):340-355

Vrugt JA, Gupta HV, Bouten W, Sorooshian S (2003) A Shuffled Complex Evolution Metropolis algorithm for optimization and uncertainty assessment of hydrologic model parameters. Water Resour Res 39(8):1201-1216

Vrugt JA, Ter Braak CJ, Gupta HV, Robinson BA (2009) Equifinality of formal (DREAM) and informal (GLUE) Bayesian approaches in hydrologic modeling? Stoch Environ Res Risk Assess 23(7):1011-1026

Williams JR (1975) Sediment routing for agricultural watersheds. J Am Water Resour Assoc 11(5):965-974

Wood GB, Wiant HV, Loy RJ, Miles JA (1990) Centroid samplinga variant of importance sampling for estimating the volume of sample trees of radiata pine. For Ecol Manage 36(2-4):233-243

Wu Y, Liu S (2012) Automating calibration, sensitivity and uncertainty analysis of complex models using the $\mathrm{R}$ package Flexible Modeling Environment (FME): SWAT as an example. Environ Model Softw 31:99-109

Yang J, Reichert P, Abbaspour KC (2007) Bayesian uncertainty analysis in distributed hydrologic modeling: a case study in the Thur River basin (Switzerland). Water Resour Res 43(10):W10401

Zak SK, Beven KJ (1999) Equifinality, sensitivity and predictive uncertainty in the estimation of critical loads. Sci Total Environ 236(1-3):191-214

Zhang X, Srinivasan R, Bosch D (2009) Calibration and uncertainty analysis of the SWAT model using Genetic Algorithms and Bayesian Model Averaging. J Hydrol 374(3-4):307-317

Zhao X, Shen ZY, Xiong M, Qi J (2011) Key uncertainty sources analysis of water quality model using the first order error method. Int J Environ Sci Technol 8(1):137-148 